\title{
Akciğerin Sklerozan Hemanjiomu: Vaka Sunumu
}

\author{
MSclerosing Hemangioma of the Lung: Case Report
}

\author{
Levent ALPAY', Şenol ÜREK ${ }^{1}$, Mesut BUZ ${ }^{1}$, Ferda AKSOY ${ }^{2}$, Hande SiMTEN ÇiFTÇỉ ${ }^{3}$, Mehmet SIRMALI $^{1}$ \\ ${ }^{1}$ Süreyyapaşa Göğüs Hastalıkları ve Göğüs Cerrahisi Eğitim ve Araştırma Hastanesi, Göğüs Cerrahisi Bölümü, İstanbul \\ ${ }^{2}$ Süreyyapaşa Göğüs Hastalıkları ve Göğüs Cerrahisi Eğitim ve Araştırma Hastanesi, Patoloji Bölümü, İstanbul \\ ${ }^{3}$ Süreyyapaşa Göğüs Hastalıkları ve Göğüs Cerrahisi Eğitim ve Araştırma Hastanesi, Anestezi Bölümü, İstanbul
}

\begin{abstract}
öz
23 yaşında erkek hasta kliniğimize göğüs grafisinde tesadüfen saptanan soliter pulmoner nodül nedeni ile başvurdu. Bilgisayarlı tomografisinde sağ üst lobta 3 cm çapında santral soliter pulmoner nodül saptandı. Pozitron emisyon tomografisinde 2.7 değerinde fluorodeoxyglucose (FDG) standart tutulum değeri (SUV) saptandı. Bronkoskopide ise normal endobronşiyal sistem gözlendi. Eksploratris torakotomide, üst lobda $3 \times 2 \mathrm{~cm}$ boyutlarında solid lezyon saptanıp wedge rezeksiyon yapıldı. Frozen kesitleri benign gelen hastanın postoperatif histopatolojisi sklerozan hemanjiom olarak raporlandı. Nadir gözlenen sklerozan hemanjiom olgumuzu literatür eşliğinde sunduk.
\end{abstract}

Anahtar Kelimeler: Akciğer, sklerozan hemanjiom, florodeoxyglucose, pozitron emisyon tomografisi.

\begin{abstract}
A 23 year old male was admitted to our clinic with an incidentally detected solitary pulmonary nodule of lung on chest X-ray. Computerized tomography showed a $3 \mathrm{~cm}$ central solitary pulmonary nodule on right upper lobe. Positron emission tomography showed a fluorodeoxyglucose accumulation with a standardized uptake value of 2.7. Bronchoscopy revealed normal endobronchial system. Wedge resection was performed to the solid lesion with $3 \times 2 \mathrm{~cm}$ diameter in the upper lobe with exploratris thoracotomy. Frozen section was benign and postoperative histopathology was reported as sclerosing hemangioma. We herein, present a case that is rarely seen with guidance of literature.
\end{abstract}

Keywords: Lung, sclerosing hemangioma, fluorodeoxyglucose, positron emission tomography. 


\section{GíRiş}

Pulmoner sklerozan hemanjiom genellikle 5 cm'den küçük çapta nadir bir akciğer neoplazmıdır (1-3). Kadınlarda daha sık görülür (5:1) ve Ortadoğu'da daha sık raporlanmıştır (4). Akciğerin sklerozan hemanjiomu değişik histolojik bileşenlerden meydana gelir. Bu tümörün histokimyasal ve ultrastrüktürel çalışması epitelyal kökene (Tip 2 pnömosit) işaret etmektedir. Ama mezotelyal, endotelyal, nöroendokrin kökeni gösteren raporlarda mevcuttur. Ayrıca sklerozan hemanjiomun neoplastik olup olmadığı tam olarak açık değildir (5). Bu yazıda, sağ üst lobta santral olarak lokalize ve düşük FDG tutulumlu bir vakayı sunduk. Akciğerin sklerozan hemanjiomu, pnömositom adıyla tanımlanan nadir görülen benign bir neoplazmdır. Genelde erişkin kadınlarda semptom olmaksızın tesadüfen çekilen akciğer grafilerinde soliter, yuvarlak, dens gölge imajı ile saptanmaktadır.

\section{OLGU SUNUMU}

23 yaşında erkek hasta rutin kontroller sırasında çekilen göğüs grafisinde sağ orta zondaki opasite nedeniyle kliniğimize interne edildi (Şekil I). Hasta asemptomatikti ve fizik muayenesi normaldi. Rutin laboratuvar tetkikleri normaldi. Sigara kullanmıyordu. Toraks bilgisayarlı tomografısınde sağ üst lobda $3 \times 2 \mathrm{~cm}$ boyutun-

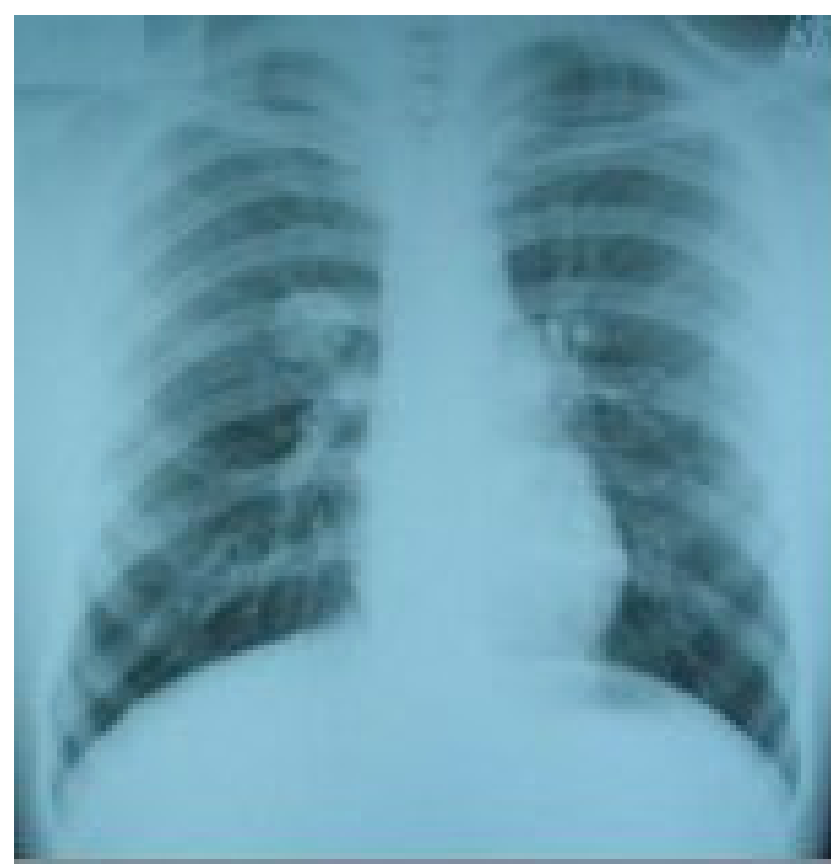

Şekil I: PA akciğer grafisinde sağ üst zonda soliter pulmoner nodül.

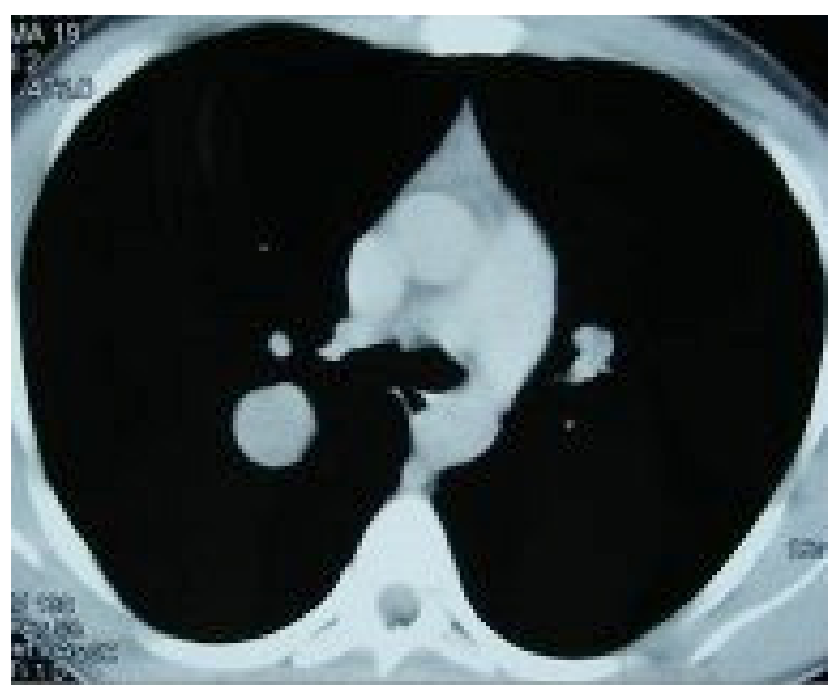

Şekil II: Akciğer BT de sağ üst lobda $3 \times 2 \mathrm{~cm}$ lik soliter pulmoner nodül.

da iyi sınırlı, kalsifikasyon içermeyen, homojen tümör mevcuttu (Şekil II). Pozitron Emisyon Tomografisi (PET) düşük tutulum gösteriyordu (Standart Tutulum Değeri: SUV: 2.7). Fiberoptik bronkoskopi normaldi. Lezyon santral lokalizasyonlu olduğu için histolojik tanıyı doğrulamak amacıyla daha fazla preoperatif değerlendirme yapılmadı. Hastaya eksploratris torakotomi uygulandı. Üst lobda santral yerleşimli yaklaşık $3 \times 2 \mathrm{~cm}$ boyutlarında lezyon saptandı. Hastaya üst lobdan wedge rezeksiyon uygulandı, lenf nodu diseksiyonu yapıldı. Yapılan frozenda kitle ve lenf nodları benign olarak raporlandı. Kitlenin histolojik incelenmesi papiller, sklerozan ve hemorajik alanlar içeren sklerozan hemanjiomu gösterdi (Şekil III). Post-operatif takibinde rekürrens yoktu.

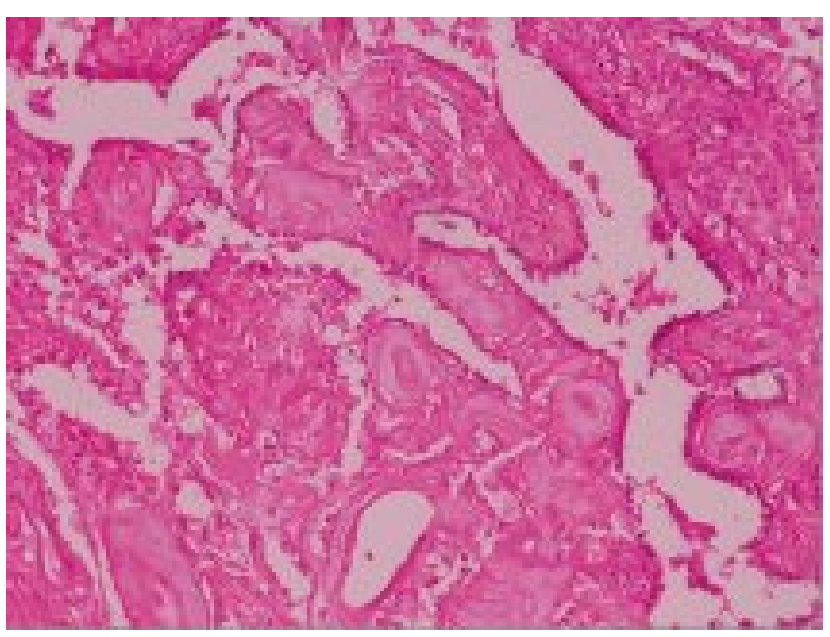

Şekil III: Sklerozan hemanjiomda papiller yapılar (HEx100). 


\section{TARTIŞMA}

Akciğer sklerozan hemanjiomları ilk kez Liebow ve Hubbell tarafından 1956 yılında tanımlanmıştır. Orta yaşlı kadınlarda daha sık görülen ve soliter pulmoner nodül şeklinde ortaya çıkan benign nitelikli nadir bir tümördür. Periferal sklerozan hemanjiomların çoğu asemptomatiktir ve rutin akciğer grafisinde insidental olarak tespit edilir. Vakalar semptomatik olduğunda bronşiyal obstrüksiyonun klinik bulguları olan öksürük, dispne ve akut bronşit gelişir (4). Yüzde dört vakada multipl lezyon görülmesine rağmen pulmoner sklerozan hemanjiomların çoğu soliter nodüldür (1). Bizim vakamız asemptomatikti ve tümör $3 \times 2 \mathrm{~cm}$ çapındaydı. Ayırıcı tanıda papiller adenom, bronşioloalveolar karsinom ve karsinoid tümör başta gelmektedir. Shisheboran ve arkadaşları endobronşiyal sklerozan hemanjiomun doğru tanısında ve lezyonun örneklenebilmesi için öncelikli olarak bronkoskopiyi önermektedir $(6,7)$. Bizim vakamızda bronkoskopide endobronşiyal sistem normaldi ve tanı tümörün rezeksiyonundan sonra kesinleşti. PET akciğer kanserli hastaların takibinde maligniteleri benign lezyonlardan ayırmada ve evrelemede kullanılır. PET malign lezyonları yakalamada hassas iken karsinoid ve bronkoalveolar karsinom gibi glukoz metabolizmasının düşük olduğu antitelerde negatif PET imajları gözlenir. İki buçuk ya da üçün altındaki SUV genellikle benign lezyonu işaret eder. Hara ve arkadaşları önemsiz derecede anormal FDG tutulumu olan sklerozan hemanjiom bildirmiştir (8). Mori ve arkadaşları yüksek derecede SUV tutan ve difüzyon Magnetik Rezonansının malign - benign lezyon ayrımında faydasının tartışıldığı bir vaka bildirmiştir (9). Biz düşük ya da önemsiz derecede artmış FDG tutulumu nedeniyle sklerozan hemanjiomun diğer benign lezyonlara benzediğini düşünüyoruz. Sklerozan hemanjiom nadir görülen benign pulmoner hastalıktır. Soliter pulmoner lezyonların ayırıcı tanısında akılda tutulmalıdır.

\section{KAYNAKLAR}

1. Hishida T, Yoshida J, Nishimura $M$, et al. Multiple sclerosing hemangioma with a 10-year history. Jpn J Clin Oncol 2005;35(1):37-9.

2. Sugio K, Yokoyama H, Kaneko S, Ishida T, Sugimachi K. Sclerosing hemangioma of the lung: radiographic and pathologic study. Ann Thorac Surg 1992; 53(2): 295-300.
3. Erdoğan $Y$ (Editör). Toraksın nadir tümörleri atatürk göğüs hastalıkları ve göğüs cerrahisi E.A.H kitabı ,Ankara: Rekmay Ltd. Şti. ,2010.

4. Devouassoux-Shisheboran $\mathrm{M}$, Hayashi T, Linnoila Rl, et al. A clinicopathologic study of 100 cases of pulmonary sclerosing hemangioma with immunohistochemical studies. TTF-1 is expressed in both round and surface cells, suggesting an origin from primitive respiratory epithelium. AM J Surg Pathol 2000; 24(7): 906-16.

5. Niho S, Suzuki K, Yokose T, et al. Monoclonality of both pale cells and cuboidal cells of sclerosing hemangioma. Am J Pathol 1998; 152(4): 1065-9.

6. Devouasoux-Shisboran M, Fouchardie A, Thivolet F, et al. Endobronchial variant of scleosing hemangioma of lung: histological and cyctological features on endobronchial material. Modern Patology 2004; 17(2): 252-7.

7. Chan ACL, Chan JKC. Pulmonary sclerosing hemangioam consistetntly thyroid transcription factor-1 (TTF-1). A new clue to its histiogenesis. Am J Surg Pathol 2000; 24(11):1531-6.

8. Hara M, Lida A, Tohyama J, et al. FDG-PET findings in sclerosing hemangioma of lung. A case report . Radiation Medicine 2001; 19(4): 215-8.

9. Mori $T$, Ohba $Y$, Shiraishi $K$, et al. A case of sclerosing hemangioma evaluated with diffusionweighted magnetic resonance imaging and 18F-Fluorodeoxyglucose positron emission tomography. Ann Thorac Cardiovasc Surg 2010; 16(4): 276-80. 